\title{
Plant morphological traits and competition index comparisons of three invasive and native submerged plants
}

\author{
Xiaolong Huang ${ }^{1}$, Jinlei $\mathrm{Yu}^{1}$, Shuailing $\mathrm{Liu}^{2}$, Hongmin $\mathrm{Xie}^{2}, \mathrm{Hu} \mathrm{He}{ }^{1}$ and Kuanyi $\mathrm{Li}^{1,3,4, *}$ \\ ${ }^{1}$ State Key Laboratory of Lake Science and Environment, Nanjing Institute of Geography and Limnology, Chinese Academy of \\ Sciences, Nanjing 210008, PR China \\ 2 Jiangsu Jiangda Eco Technology Co., Ltd., Wuxi 214135, PR China \\ 3 Sino-Danish College, University of Chinese Academy of Sciences, Beijing 100049, PR China \\ ${ }^{4}$ College of Environmental and Chemical Engineering, Chongqing Three Gorges University, Wanzhou 404000, PR China
}

Received: 7 January 2021 / Accepted: 1 March 2021

\begin{abstract}
The submerged species Carolina fanwort (Cabomba caroliniana) has attracted considerable attention in Lake Taihu Basin (LTB), China. This species was widely used as a garden plant until 2016, when it was identified as invasive. In this study, we conducted a mesocosm experiment to compare the morphological traits, includingtotal dry mass, shoot/root $(\mathrm{S} / \mathrm{R})$ ratio, relative growth rate (RGR) and competition index $\log$ response ratio $(\ln R R)$, of $C$. caroliniana and two frequently co-occurring native submerged plants, water thyme (Hydrilla verticillata) and Eurasian watermilfoil (Myriophyllum spicatum). The results demonstrated that $C$. caroliniana did not show more advantageous traits (higher total dry mass, $\mathrm{S} / \mathrm{R}$ ratio and $\mathrm{RGR}$ ) or have a lower $\ln R R$ than $H$. verticillata or $M$. spicatum. We provide a counterexample to commonly accepted thought in which the successful invasion of invasive species may not be explained by outcompeting native plants. Other biotic or abiotic factors that determine the successful invasion of C. caroliniana must be studied further.
\end{abstract}

Keywords: Biological invasion / Cabomba caroliniana / competition ability / Lake Taihu Basin

Résumé - Comparaison de leurs caractéristiques morphologiques et de l'indice de compétition de trois plantes submergées envahissantes et indigènes. L'espèce submergée " éventail de Caroline » (Cabomba caroliniana) a suscité une attention considérable dans le bassin du lac Taihu (LTB), en Chine. Cette espèce a été largement utilisée comme plante de jardin jusqu'en 2016, date à laquelle elle a été identifiée comme envahissante. Dans cette étude, nous avons mené une expérience en mésocosme pour comparer les caractéristiques morphologiques, y compris la masse sèche totale, le rapport pousse/racine $(\mathrm{S} / \mathrm{R})$, le taux de croissance relatif (RGR) et le rapport logarithmique de réponse de l'indice de compétition (ln $R R$ ), de C. caroliniana et de deux plantes submergées indigènes fréquemment co-occurrentes, L'hydrille verticillée (Hydrilla verticillata) et le myriophylle à épi (Myriophyllum spicatum). Les résultats ont démontré que $C$. caroliniana ne présentait pas de caractéristiques plus avantageuses (masse sèche totale, rapport $\mathrm{S} / \mathrm{R}$ et RGR plus élevés) ou avait un $\ln R R$ plus faible que $H$. verticillata ou $M$. spicatum. Nous fournissons un contre-exemple à la pensée communément admise selon laquelle le succès de l'invasion d'espèces envahissantes peut ne pas s'expliquer par la supplantation des plantes indigènes. D'autres facteurs biotiques ou abiotiques qui déterminent le succès de l'invasion de $C$. caroliniana doivent être étudiés plus avant.

Mots clés : Invasion biologique / Cabomba caroliniana / capacité de compétition / bassin du lac Taihu

\section{Introduction}

With the development of economic globalisation, exchanges among different countries and regions have become more frequent, and an increasing number of introduced species

\footnotetext{
*Corresponding author: kyli@niglas.ac.cn
}

have been intentionally or unintentionally brought into new areas (Xu et al., 2006; Hussner et al., 2017; Wu and Ding, 2019). Successful invasive species constitute a minority of introduced species (Nentwig, 2008). However, they have resulted in reduced abundance and diversity of native species in invaded natural habitats and cause harm to human society (Lowe et al., 2000; Goodenough, 2010; Vilà et al., 2011; 
Reshi et al., 2013). Invasive aquatic plants are strong competitors (Lacoul and Freedman, 2006). The successful invasion of an invasive species depends on its specific traits (for instance, functional traits), and successful invaders may have advantageous traits over native species. This thought dates back to The Genetics of Colonizing Species by Baker, who is a pioneer in invasion biology (Baker and Stebbins, 1965). Invasive species, normally prone to exhibiting advantageous functional traits over native species, can change the native plant structure and reduce diversity via out competing these plants and/or interfering in competition to exclude native species in biological communities (Hamilton et al., 2005; van Kleunen et al., 2010a; Caplan and Yeakley, 2013; Mathakutha et al., 2019). van Kleunen et al. (2010b) also showed that invasive plant species have significantly higher trait values than non-invasive species in a meta-analysis study. In freshwater ecosystems, invasive aquatic plants cause the extinction of native aquatic plants, loss of fish abundance and reduction of benthos, which significantly change freshwater ecosystems (Gallardo et al., 2016; Michelan et al., 2018; Wu and Ding, 2019). Nearly 24\% of the plants listed in the 100 of the World's Worst Invasive Alien Species by the International Union for Conservation of Nature (IUCN) were aquatic plants, which is disproportionate to the area of freshwater habitats (less than 6\%) on the earth (Zedler and Kercher, 2004).

By the end of 2016, more than 600 invasive species had been found in China, including nearly 50 of the species identified in the above list (Zhan et al., 2017). The flourishing breeding industries for red swamp crayfishes (Procambarus clarkia) and hairy crabs (Eriocheir sinensis) have introduced a large number of highly palatable plants, many of which are invasive (Jiang et al., 2011). Additionally, with the increasing prosperity of the aquarium market, a variety of ornamental aquatic plants have been introduced into China (Wang et al., 2016; Yu et al., 2018). Among these, the invasive plant Carolina fanwort (Cabomba caroliniana) has been a dominant submerged plant in some areas of the Lake Taihu basin (LTB) (Huang et al., 2020). This plant has only recently been included in the List of Invasive Species in China (Ministry of Ecology and Environment (MEE), 2016). Before being listed, it was widely used as a garden wetland plant in ecological restoration, especially in the area downstream of the LTB. Its invasiveness has gained considerable attention; however, it seems there is no conclusion regarding how this invasive plant is successfully invading China.

To our knowledge, no previous competitiveness comparisons have been conducted among $C$. caroliniana and co-occurring native plants. In this study, the morphological traits (total dry mass, shoot/root $(\mathrm{S} / \mathrm{R})$ ratio, relative growth rate (RGR) and competitive ability index log response ratio (ln $R R)$ ) of $C$. caroliniana and two co-occurring species (water thyme (Hydrilla verticillata) and Eurasian watermilfoil (Myriophyllum spicatum)), were evaluated in a mesocosm experiment. As competition will hamper the biomass and growth of plants, comparisons of these associated traits will reflect the relationship among plants (Grotkopp et al., 2002; Wang et al., 2008b; Dawson et al., 2012; Shen et al., 2019). Two questions were posed: (1) Does $C$. caroliniana have more advantageous traits than native species? (2) Can C. caroliniana out compete native counterparts within the invaded area?

\section{Materials and methods}

\subsection{Study area}

The mesocosm experiment was conducted in the Taihu Laboratory for Lake Ecosystem Research (TLLER) $\left(31.4198^{\circ} \mathrm{N}, 120.2159^{\circ} \mathrm{E}\right)$, which is one of the national field stations of the Chinese National Ecosystem Research Network (CNERN) in Wuxi City, Jiangsu Province. Downstream of the Yangtze River, the LTB is one of the most prosperous areas in China. It contains $1 / 22$ of the total population but contributed nearly $1 / 10$ of the gross domestic product (GDP) of China in 2018 (Taihu Basin Authority (TBA), 2019).

\subsection{Plant materials}

Three commonly co-occurring submerged plants in the LTB, the native $H$. verticillata, $M$. spicatum, and the invasive C. caroliniana, were used in this study. Before the experiment began, we conducted an aquatic plant field reconnaissance investigation in the LTB. Sampling quadrats with an area of $1 \times 1 \mathrm{~m}^{2}$ were randomly selected. The plant coverage was calculated as the species coverage/all species coverage ratio in a sampling quadrat. The results showed that within $1 \times 1 \mathrm{~m}^{2}$ mature mono-species community quadrats, when the plant coverage was $95 \%$ (in freshwater ecosystems, it is rare for plants to show $100 \%$ coverage, as gaps among species always exist), the average density of $H$. verticillata was $42 / \mathrm{m}^{2}$ (estimated density was $44 / \mathrm{m}^{2}$ for $100 \%$ coverage), the average density of $M$. spicatum was $32 / \mathrm{m}^{2}$ (estimated density was 34 for $100 \%$ coverage), and the average density of C. caroliniana was $35 / \mathrm{m}^{2}$ (estimated density was $37 / \mathrm{m}^{2}$ for $100 \%$ coverage). The same plant density was used as high-density treatment (H2M2C2) accordingly to the experiment bucket (basal area $=0.16 \mathrm{~m}^{2}$ and $\mathrm{h}=0.76 \mathrm{~m}$ ) in the experiment (Tab. 1). Half of the high densities were used as medium-density treatment (HIM1C1) (Tab. 1). In the mono-species treatments (H1, M1 and C1), one shoot of each species was cultivated individually, and for low-density treatment, one shoot of these species was cultivated together (Tab. 1).

\subsection{Experimental design}

Young shoots of the three species were collected and cultivated at the TLLER for one month. The experiment began on June 20th, 2018. Two factors were set in the experiment: the plant species and density. At the beginning of the experiment, $20 \mathrm{~cm}$ of lake sediment from the Lake Taihu was collected, mixed, and then added to each bucket. The lake water was filtered with a sieve and then poured into the buckets to $40 \mathrm{~cm}$ (measured from the bottom of the bucket). The lake water parameters were total dissolved nitrogen $(\mathrm{TDN})=0.71 \pm 0.11$, total dissolved phosphorus $(\mathrm{TDP})=$ $0.052 \pm 0.007$, dissolved oxygen $(\mathrm{DO})=4.26 \pm 0.67 \mathrm{mg} / \mathrm{L}$, conductivity $=395 \pm 46 \mu \mathrm{S} / \mathrm{cm}$ and $\mathrm{pH}=7.93 \pm 1.6$ (mean \pm S.D.) during the experimental period. The TDN and TDP were measured once aweek, and the other parameters were measured twice a week. Young shoots measuring 20-25 cm from the three species were selected and planted in the 
Table 1. Plant density calculation for the mesocosm experiment.

\begin{tabular}{|c|c|c|c|c|c|c|c|c|}
\hline & \multicolumn{3}{|c|}{ CK } & \multirow{2}{*}{$\frac{\text { Low-density }}{\text { H1M1C1 }}$} & \multicolumn{3}{|c|}{ Medium-density } & \multirow{2}{*}{$\frac{\text { High-density }}{\mathrm{H} 2 \mathrm{M} 2 \mathrm{C} 2}$} \\
\hline & $\mathrm{H} 1$ & M1 & $\mathrm{C} 1$ & & $\mathrm{H} 2 \mathrm{M} 2$ & $\mathrm{M} 2 \mathrm{C} 2$ & $\mathrm{H} 2 \mathrm{C} 2$ & \\
\hline Hydrilla verticillata & 1 & 0 & 0 & 1 & 2 & 2 & 0 & 2 \\
\hline Myriophyllum spicatum & 0 & 1 & 0 & 1 & 2 & 0 & 2 & 2 \\
\hline Cabomba caroliniana & 0 & 0 & 1 & 1 & 0 & 2 & 2 & 2 \\
\hline Total plants & 1 & 1 & 1 & 3 & 4 & 4 & 4 & 6 \\
\hline Total densities $\left(/ \mathrm{m}^{2}\right)$ & 6 & 6 & 6 & 19 & 25 & 25 & 25 & 38 \\
\hline
\end{tabular}

Two factors were established: the plant species (Hydrilla verticillata, Myriophyllum spicatum and Cabomba caroliniana) and the density. In the mono-species treatments (H1, M1, and C1), one shoot from each species was transplanted individually into mesocosms. In the mixed treatments, shoots from the three plant species were transplanted and received mixed treatments (low-density: H1M1C1; medium-density: H2M2, M2C2, and $\mathrm{H} 2 \mathrm{C} 2$; and high-density: $\mathrm{H} 2 \mathrm{M} 2 \mathrm{C} 2$ ). The low, medium and high plant densities of the three plant species were evaluated during an aquatic plant field investigation within $1 \times 1 \mathrm{~m}^{2}$ mono-species quadrats in the Lake Taihu drainage basin. The total densities were calculated according to the bucket basal area $\left(0.16 \mathrm{~m}^{2}\right)$.

Table 2. Two-way ANOVA results regarding the plant species and density for the plant total biomass, shoot/root (S/R) ratio, relative growth rate (RGR), and competition index $\ln R R$ during the experiment.

\begin{tabular}{|c|c|c|c|c|c|c|c|c|c|}
\hline & \multicolumn{3}{|c|}{ Plant species } & \multicolumn{3}{|c|}{ Plant density } & \multicolumn{3}{|c|}{ Species $\times$ density } \\
\hline & d.f. & $F$ & $P$ & d.f. & $F$ & $P$ & d.f. & $F$ & $P$ \\
\hline Total biomass & 2 & 328.409 & $<\mathbf{0 . 0 0 1}$ & 3 & 8.273 & $<\mathbf{0 . 0 0 1}$ & 6 & 1.099 & 0.373 \\
\hline $\mathrm{S} / \mathrm{R}$ ratio & 2 & 8.771 & $<\mathbf{0 . 0 0 1}$ & 3 & 1.077 & 0.365 & 6 & 6.253 & $<\mathbf{0 . 0 0 1}$ \\
\hline RGR & 2 & 217.639 & $<\mathbf{0 . 0 0 1}$ & 3 & 10.032 & $<\mathbf{0 . 0 0 1}$ & 6 & 3.368 & 0.006 \\
\hline $\ln R R$ & 2 & 12.061 & $<\mathbf{0 . 0 0 1}$ & 3 & 11.685 & $<\mathbf{0 . 0 0 1}$ & 6 & 4.072 & 0.002 \\
\hline
\end{tabular}

Significance levels of $P<0.05$ are highlighted in bold.

buckets (Tab. 1). Each treatment had five replicates $(n=5)$, and 40 buckets were used. After one week, all the plants survived, and appeared to have acclimated to the new environment (Li et al., 2015; Li et al., 2016; Huang et al., 2018). The water level in each bucket was then increased to $75 \mathrm{~cm}$ (measured from the bottom of the bucket). The plants were harvested when flower buds of M. spicatum and $H$. verticillata appeared, which indicated that they had reached the end of vegetative growth on August 4th, 2018.

The plant shoot/root $(\mathrm{S} / \mathrm{R})$ biomass ratio was calculated as follows:

$\mathrm{S} / \mathrm{R}$ ratio = shoot biomass/root biomass;

The relative growth rate (RGR) was calculated as follows (Gillard et al., 2017):

$\mathrm{RGR}\left(\mathrm{mg} \cdot \mathrm{g}^{-1} \cdot \mathrm{d}^{-1}\right)=\left(\ln r_{2}-\ln r_{1}\right) /\left(t_{2}-t_{1}\right) ;$

where $r_{1}$ is the initial dry plant biomass at initial time $t_{1}$; and $r_{2}$ is the dry plant biomass at harvest time $t_{2}$. In this study, $t_{2}-t_{1}=45 \mathrm{~d}$.

The competition index $\log$ response ratio $(\ln R R)$ was calculated as follows (Goldberg et al., 1999; Hedges et al., 1999; Weigelt and Jolliffe, 2003):

$$
\ln R R=\ln \left(r_{\text {mono }} / r_{\text {mix }}\right)
$$

where $r_{\text {mono }}$ represents the total dry mass of a single plant in a bucket (in the absence of competition, namely, H1, M1 and M1 in this study) and $r_{\text {mix }}$ represents the average total dry mass of a plant in a bucket containing more than one plant. A higher $\ln R R$ indicates more intraspecific and/or interspecific competition intensity.

\subsection{Data analysis}

A two-way ANOVA was applied with plant species and density as the primary factors to test their effects on plant traits in the competition experiment. When a significant treatment effect was detected, post hoc pairwise comparisons of the means were performed to examine the differences between treatments using Duncan's multiple range test for multiple comparisons.

\section{Results}

The three species, $H$. verticillata, $M$. spicatum, and C. caroliniana, exhibited significant differences $(P<0.05)$ in the plant total dry mass, $\mathrm{S} / \mathrm{R}$ ratio, RGR and $\ln R R$, which indicates the occurrence of significant differences among these plant species (Tab. 2). The plant density had a significant influence $(P<0.05)$ on all the plant trait values except for the $\mathrm{S} / \mathrm{R}$ ratio (Tab. 2), and the interaction between the plant species and density was significant for all the measured plant trait values except for the total dry mass (Tab. 2).

\subsection{Morphological traits}

The native plant $M$. spicatum showed a relatively higher total dry mass in the mono-species treatment M1 and low-density treatment $\mathrm{H} 1 \mathrm{M} 1 \mathrm{C} 1$ compared with the other 


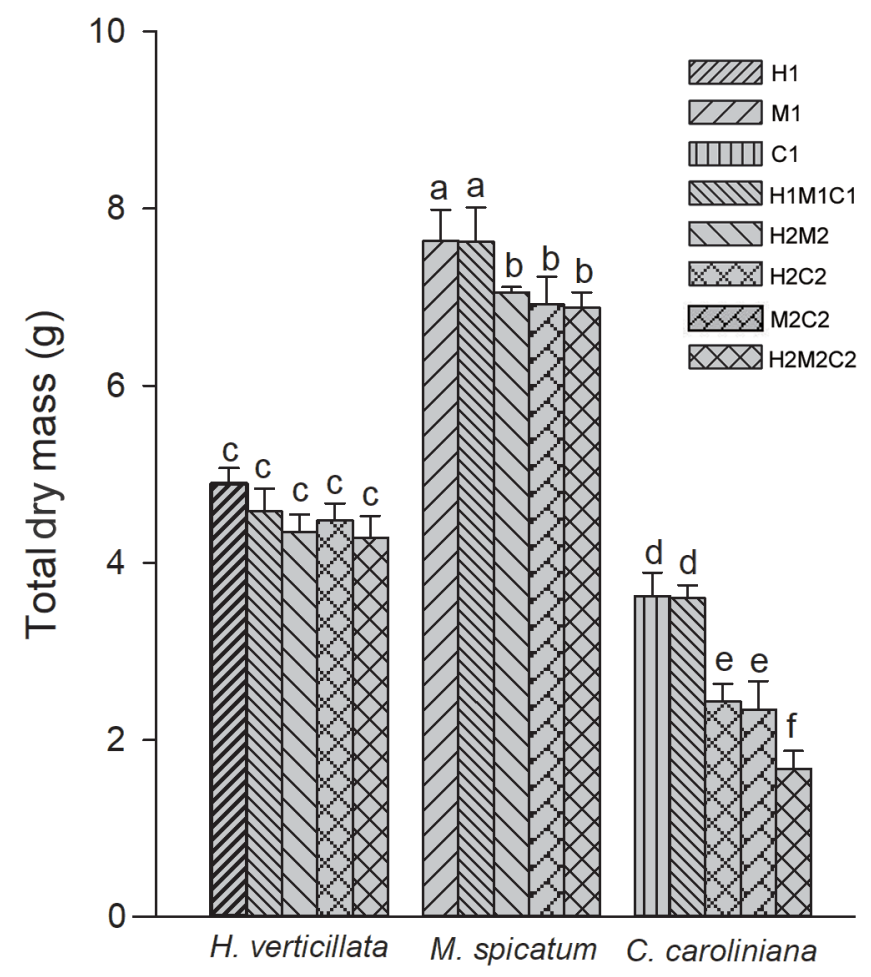

Fig. 1. The plant trait total dry mass of different treatments of Hydrilla verticillata, Myriophyllum spicatum, and Cabomba caroliniana in the experiment. The values are the means \pm SE. Different lowercase letters indicate significant differences among treatments.

treatments. The total dry mass for the native plant H.verticillata did not show significant differences, but a decreasingtrend was detected for the invasive plant C. caroliniana (Fig. 1).

The highest $\mathrm{S} / \mathrm{R}$ ratio was obtained for the no competition treatment $\mathrm{C} 1$, namely, the treatment that involves one C. caroliniana plant, and it decreased with an increase in the plant density (Fig. 2). Conversely, the S/R ratio increased with an increase in plant density for $H$. verticillata, and M. spicatum showed a relatively stable fluctuation (Fig. 2).

Myriophyllum spicatum had the highest RGR among all the treatments, followed by $H$. verticillata, while $C$. caroliniana showed a decreasing trend with increasing plant density (Fig. 3).

\subsection{Competition intensity}

The competition intensity, as measured by the competition index $\ln R R$, showed a similar trend among the three plant species (Fig. 4). Cabomba caroliniana, as well as the other two plant species had the highest value for the high-density treatment $\mathrm{H} 2 \mathrm{M} 2 \mathrm{C} 2$, followed by the medium-density treatments $\mathrm{M} 2 \mathrm{C} 2$ and $\mathrm{H} 2 \mathrm{C} 2$, while the value for the low-density treatment $\mathrm{H} 1 \mathrm{M} 1 \mathrm{C} 1$ was the lowest (Fig. 4).

\section{Discussion}

\subsection{The successful invasion of $C$. caroliniana may not be caused by outcompeting native species}

In this study, we found that invasive $C$. caroliniana did not show more advantageous traits or a lower competition index

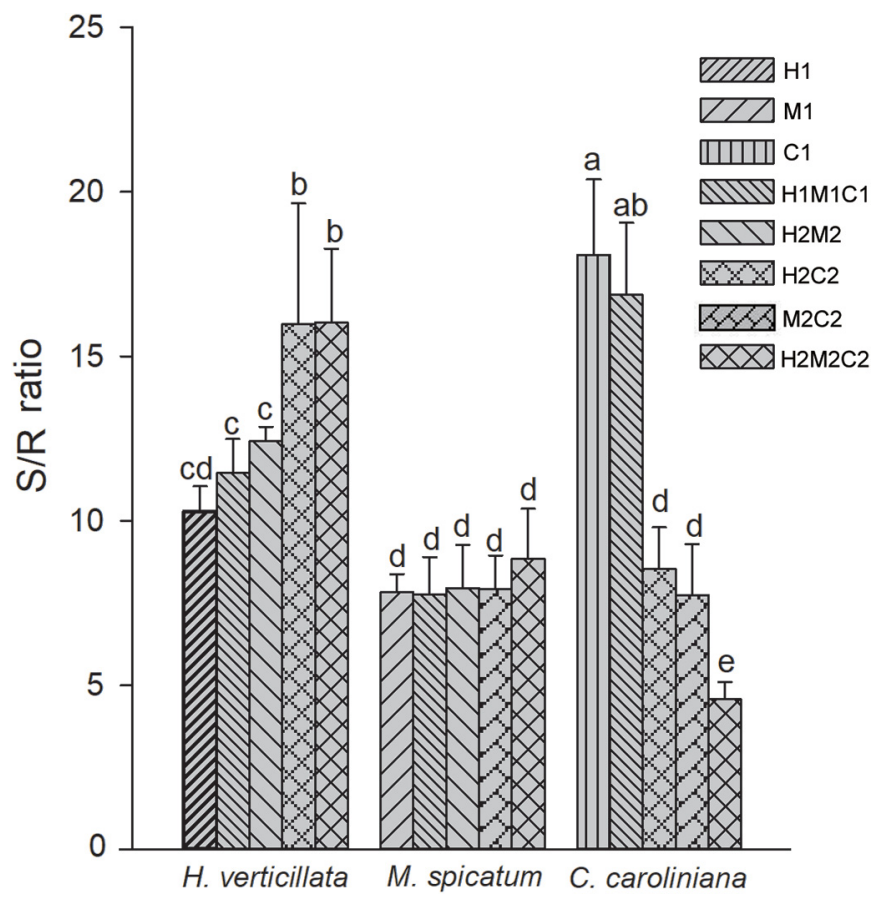

Fig. 2. The Plant trait shoot/root (S/R) ratio of different treatments of Hydrilla verticillata, Myriophyllum spicatum, and Cabomba caroliniana in the experiment. The values are the means \pm SE. Different lowercase letters indicate significant differences among treatments.

than those of the native $H$. verticillata or $M$. spicatum of the same life-form. The three submerged species can coexist at low density, but high density will lead to competition and result in the inhibition of $C$. caroliniana. This result contradicted previous findings showing that invasive species had more advantageous traits or a higher competitive ability than native species.

As primary producers, biomass accumulation is perhaps the most important manifestation of biological vegetative growth of aquatic plants (Fan et al., 2015; Dalla Vecchia et al., 2020). In this study, C. caroliniana did not show a higher total dry mass and a decreasing trend when the density of its native counterparts $M$. spicatum or $H$. verticillata increased, which indicates that the plant may not win competition by showing high biomass production.Biomass allocation is an adaptive strategy developed by plants in response to ecological factors (Barrat-Segretain, 2001; Wang et al., 2008b). Although $C$. caroliniana have the highest $\mathrm{S} / \mathrm{R}$ ratio in mono-species treatment $\mathrm{C} 1$ (Fig. 2), it shows a decreasing trend when plant density increases, which may indicate that the shoot growth of the plant is suppressed by the two other species while the root is less affected.

Competition is the most common negative interaction among different plants; it is a mutual relationship between two or more plants when the required environmental resources or space are relatively insufficient (Goldberg et al., 1999). Some plants are more efficient in obtaining resources or can occupy more space, thus limiting the survival of other plants (Weigelt and Jolliffe, 2003). Normally, invasive plants are believed to have a higher RGR (Richards et al., 2006; Dawson et al., 2011). 


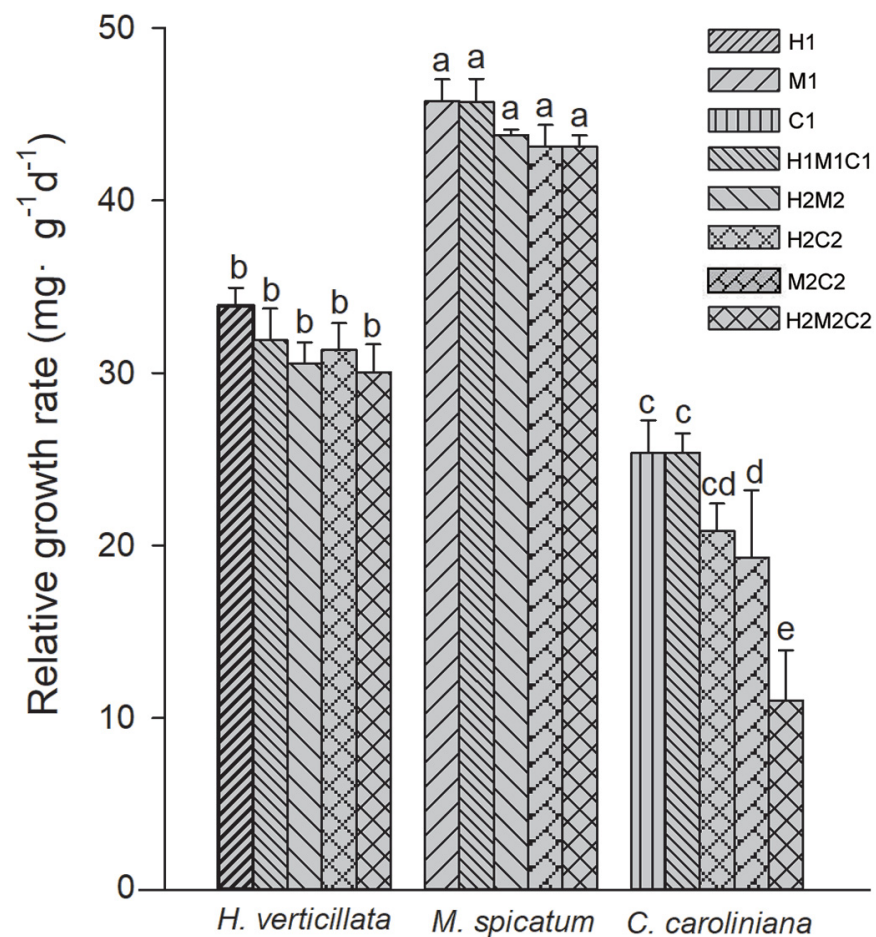

Fig. 3. The plant trait relative growth rate (RGR) of different treatments of Hydrilla verticillata, Myriophyllum spicatum, and Cabomba caroliniana in the experiment. The values are means $\pm \mathrm{SE}$. Different lowercase letters indicate significant differences among treatments.

A recent study also showed that intrinsic growth rates (similar to RGR) are more important than competitive ability, as introduced plants were shown to have higher intrinsic growth rates than those of native plants (Zhang and van Kleunen, 2019). However, we did not record this tendency in C. caroliniana (Fig. 4). The less advantageous traits of C. caroliniana may indicate that the successful invasion of this plant was not supported by directly outcompeting native plants. This result emphasised its weak competitive ability in invaded habitats, which indicates that other factors, biotic or abiotic factors, affecting the successful invasion of this species should be considered.

\subsection{Implications for the control of invasive submerged plants}

Submerged plants are probably the most important group of aquatic plants, as they provide the fundamental functions and structures of freshwater ecosystems (Scheffer, 2004; Lacoul and Freedman, 2006). As $C$. caroliniana has been a successful invader in China, it has caused serious and widespread effects (Liu et al., 2018). It seems that no successful removal measures have been identified for the plant, and the only proven successful method is manual removal; during this process, the plant is easily broken into fragments and washed away with the water flow (Fig. 5). Under certain conditions, new populations can be colonized, which may lead to new populations (Ørgaard, 1991; Schooler et al., 2006; Jacobs and Macisaac, 2009; Lima et al., 2014; Bickel, 2015,

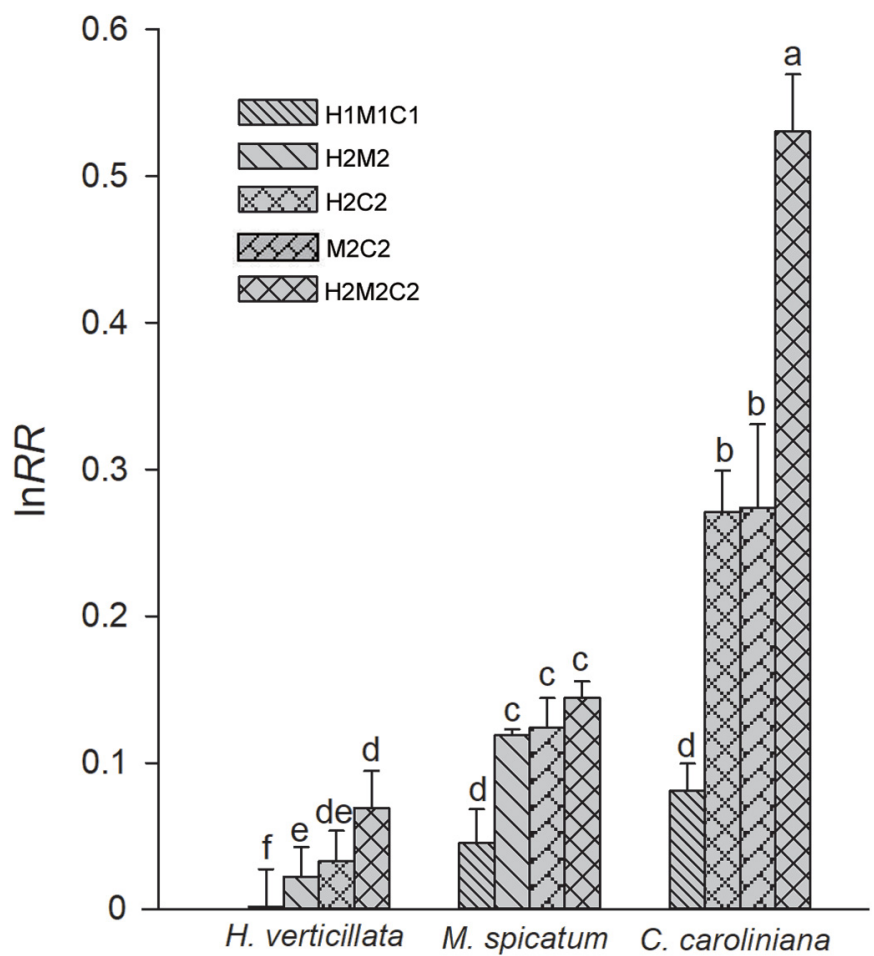

Fig. 4. The plant trait competition index $\log$ response ratio $(\ln R R)$ of different treatments of Hydrilla verticillata, Myriophyllum spicatum, and Cabomba caroliniana in the experiment. The values are the means \pm SE. Different lowercase letters indicate significant differences among treatments.

2017; Scheers et al., 2019). A realistic and feasible control method for this plant seems difficult.

Myriophyllum spicatum is the most studied aquatic plant species in the scientific literature (Dalla Vecchia et al., 2020). It is a native plant in China but an invasive plant in other countries, especially North America (Gassmann et al., 2006; Li et al., 2016; Hussner et al., 2017; Smith et al., 2021). A large ecological amplitude,low palatability, high nutrient-capturing ability and diverse mechanisms of propagation (seed, rhizome production, and stem segment) enable colonization by this species (Wang et al., 2008a; Bosch et al., 2009; Li et al., 2015; Yu et al., 2016; Son et al., 2017). In this study, we showed that M. spicatum has relatively higher values for certain traits and competitive abilities than $C$. caroliniana which may indicate that it is an already quite aggressive species. Other traits of this species and their responses to environmental factors, as well as those of other plant species and herbivores remain to be investigated.

Hydrilla verticillata is native to Asia and is a successful invasive submerged plant throughout the world (Bellinger and Davis, 2017). This plant is adapted to various environmental conditions and has a unique $\mathrm{C} 4$ photosynthesis mechanism and a broad ecological amplitude, which causes the suppression of the native aquatic plant community (Bowes et al., 2002; Sousa, 2011). It has been attempted but found to be ineffective as a biological control method for $C$. caroliniana (Schooler et al., 2012). Thus, conducting common-garden experiments with the three plants in invaded and non-invaded areas may be helpful for understandingthe invasion and control of these plants. 


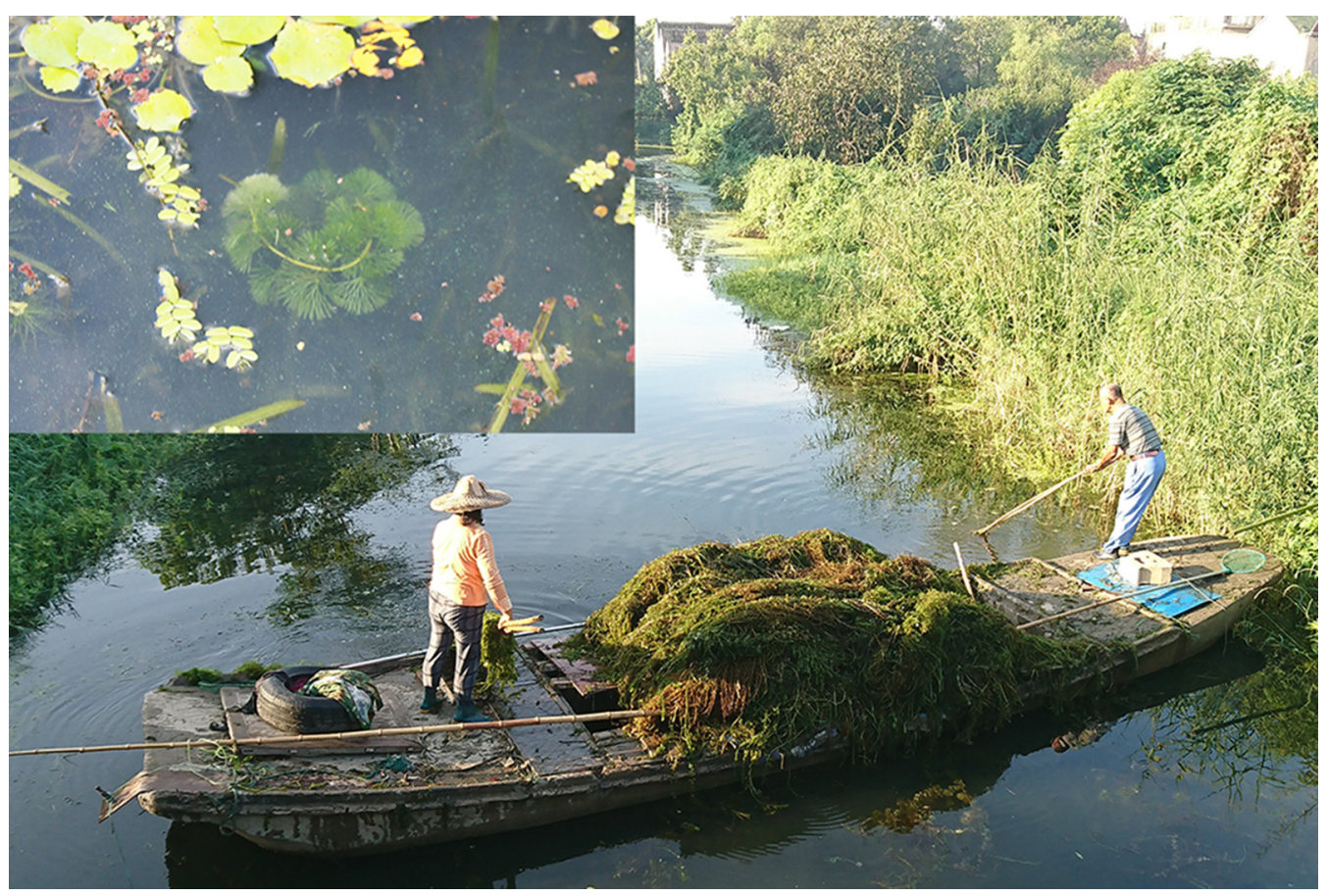

Fig. 5. The manual removal of Cabomba caroliniana in a river channel $\left(31.4224^{\circ} \mathrm{N}, 120.2165^{\circ} \mathrm{E}\right)$ near TLLER in the Lake Taihu Basin. The removal process can produce plant stem fragments (image in the top left corner). Both photographs were taken by the first author.

\section{Conclusions}

In this study, we conducted a mesocosm experiment to evaluate the morphological traits and competitive ability of the invasive plant $C$. caroliniana and two of its commonly co-occurring native submerged plants $H$. verticillata and $M$. spicatum. In total, $C$. carolinianadid not show more advantageous traits. Thus, we provide a counterexample in which the successful invasion of a submerged species may not be explained by successful competition over native plants. Other biotic or abiotic factors should be explored to explain the widespread distribution of this invasive species.

Acknowledgments. The authors acknowledge funding support from the National Science Foundation of China (NSFC) (31930074 and 32001157), the Science and Technology Service Network Initiative (KFJ-STS-QYZD-156) of the Chinese Academy of Sciences (CAS), and National Science and Technology Fundamental Resources Investigation Program of China (2019FY100600).

\section{References}

Baker HG, Stebbins GL. 1965. The genetics of colonizing species. New York: Academic Press.

Barrat-Segretain M. 2001. Biomass allocation in three macrophyte species in relation to the disturbance level of their habitat. Freshw Biol 46: 935-945.

Bellinger BJ, Davis SL. 2017. Investigating the role of water and sediment chemistry from two reservoirs in regulating the growth potential of Hydrilla verticillata (L.f.) Royle and Cabomba caroliniana A. Gray. Aquat Bot 136: 175-185.
Bickel TO. 2015. A boat hitchhiker's guide to survival: Cabomba caroliniana desiccation resistance and survival ability. Hydrobiologia 746: 123-134.

Bickel TO. 2017. Processes and factors that affect regeneration and establishment of the invasive aquatic plant Cabomba caroliniana. Hydrobiologia 788: 157-168.

Bosch I, Makarewicz JC, Bonk EA, Ruiz C, Valentino M. 2009. Responses of lake macrophyte beds dominated by Eurasian watermilfoil (Myriophyllum spicatum) to best management practices in agricultural sub-watersheds: Declines in biomass but not species dominance. J Great Lakes Res 35: 99-108.

Bowes G, Rao SK, Estavillo GM, Reiskind JB. 2002. C4 mechanisms in aquatic angiosperms: comparisons with terrestrial $\mathrm{C} 4$ systems. Funct Plant Biol 29: 379.

Caplan JS, Yeakley JA. 2013. Functional morphology underlies performance differences among invasive and non-invasive ruderal Rubus species. Oecologia 173: 363-374.

Dalla Vecchia A, Villa P, Bolpagni R. 2020. Functional traits in macrophyte studies: Current trends and future research agenda. Aquat Bot 167: 103290.

Dawson W, Fischer M, van Kleunen M. 2011. The maximum relative growth rate of common UK plant species is positively associated with their global invasiveness. Global Ecol Biogeogr 20: 299-306.

Dawson W, Fischer M, van Kleunen M. 2012. Common and rare plant species respond differently to fertilisation and competition, whether they are alien or native. Ecol Lett 15: 873-880.

Fan S, Yu H, Liu C, Yu D, Han Y, Wang L. 2015. The effects of complete submergence on the morphological and biomass allocation response of the invasive plant Alternanthera philoxeroides. Hydrobiologia 746: 159-169.

Gallardo B, Clavero M, Sánchez MI, Vilà M. 2016. Global ecological impacts of invasive species in aquatic ecosystems. Global Change Biol 22: 151-163. 
Gassmann A, Cock MJW, Shaw R, Evans HC. 2006. The potential for biological control of invasive alien aquatic weeds in Europe: a review. Hydrobiologia 570: 217-222.

Gillard M, Thiébaut G, Rossignol N, Berardocco S, Deleu C. 2017. Impact of climate warming on carbon metabolism and on morphology of invasive and native aquatic plant species varies between spring and summer. Environ Exp Bot 144: 1-10.

Goldberg DE, Rajaniemi T, Gurevitch J, Stewart-Oaten A. 1999. Empirical approaches to quantifying interaction intensity: competition and facilitation along productivity gradients. Ecology 80: $1118-1131$.

Goodenough A. 2010. Are the ecological impacts of alien species misrepresented? A review of the "native good, alien bad" philosophy. Community Ecol 11: 13-21.

Grotkopp E, Rejmánek M, Rost TL. 2002. Toward a causal explanation of plant invasiveness: Seedling growth and Life-history strategies of 29 pine (Pinus) species. Am Nat 159: 396-419.

Hamilton MA, Murray BR, Cadotte MW, Hose GC, Baker AC, Harris CJ, Licari D. 2005. Life-history correlates of plant invasiveness at regional and continental scales. Ecol Lett 8: 1066-1074.

Hedges LV, Gurevitch J, Curtis PS. 1999. The meta-analysis of response ratios in experimental ecology. Ecology 80: 1150-1156.

Huang X, Shen N, Guan X, Xu X, Kong F, Liu C, Yu D. 2018. Root morphology and structure comparisons of native and introduced aquatic plant species in multiple substrates. Aquat Ecol 52: 65-76.

Huang X, Xu X, Guan B, Liu S, Xie H, Li Q, Li K. 2020. Transformation of aquatic plant diversity in an environmentally sensitive area, the Lake Taihu drainage basin. Front Plant Sci 11: 513788 .

Hussner A, Stiers I, Verhofstad MJJM, Bakker ES, Grutters BMC, Haury J, van Valkenburg JLCH, Brundu G, Newman J, Clayton JS, Anderson LWJ, Hofstra D. 2017. Management and control methods of invasive alien freshwater aquatic plants: a review. Aquat Bot 136: $112-137$.

Jacobs MJ, Macisaac HJ. 2009. Modelling spread of the invasive macrophyte Cabomba caroliniana. Freshw Biol 54: 296-305.

Jiang H, Fan Q, Li J, Shi S, Li S, Liao W, Shu W. 2011. Naturalization of alien plants in China. Biodivers Conserv 20: 1545-1556.

Lacoul P, Freedman B. 2006. Environmental influences on aquatic plants in freshwater ecosystems. Environ Rev 14: 89-136.

Li F, Zhu L, Xie Y, Jiang L, Chen X, Deng Z, Pan B. 2015. Colonization by fragments of the submerged macrophyte Myriophyllum spicatum under different sediment type and density conditions. Sci Rep 5: 11821.

Li F, Qin Y, Zhu L, Xie Y, Liang S, Hu C, Chen X, Deng Z. 2016. Effects of fragment size and sediment heterogeneity on the colonization and growth of Myriophyllum spicatum. Ecol Eng 95: 457-462.

Lima CTD, Santos FDAR, Giulietti AM. 2014. Morphological strategies of Cabomba (Cabombaceae), a genus of aquatic plants. Acta Bot Bras 28: 327-338.

Liu X, Han Y, Zhu J, Deng J, Hu W, Da Silva TEV. 2018. Will elevated atmospheric $\mathrm{CO}_{2}$ boost the growth of an invasive submerged macrophyte Cabomba caroliniana under the interference of phytoplankton? Environ Sci Pollut R 25: 1809-1821.

Lowe S, Browne M, Boudjelas S, De Poorter M. 2000. 100 of the World's Worst Invasive Alien Species A selection from the Global Invasive Species Database. The Invasive Species Specialist Group
(ISSG) a specialist group of the Species Survival Commission (SSC) of the World Conservation Union (IUCN).

Mathakutha R, Steyn C, le Roux PC, Blom IJ, Chown SL, Daru BH, Ripley BS, Louw A, Greve M. 2019. Invasive species differ in key functional traits from native and non-invasive alien plant species. $J$ Veg Sci 30: 994-1006.

Michelan TS, Thomaz SM, Bando FM, Bini LM. 2018. Competitive effects hinder the recolonization of native species in environments densely occupied by one invasive exotic species. Front Plant Sci 9: 1261.

Ministry of Ecology and Environment (MEE). 2016. the List of alien invasive species in China's natural ecosystem. http://sts.mee.gov. cn/swaq/lygz/201708/t20170828_420478.shtml (in Chinese).

Nentwig W. 2008. Traits of a good invader. In: Nentwig W, ed. Biological Invasions. Berlin and Heidelberg: Springer-Verlag, pp. 75-96.

Ørgaard M. 1991. The genus Cabomba (Cabombaceae) - a taxonomic study. Nord J Bot 11: 179-203.

Reshi ZA, Rasoo N, Dar PA, Rehman W, Shah MA. 2013. Impact of invasive alien plant species on aboveground and belowground species diversity in the Kashmir Himalaya, India. In: Jose S, Singh HP, Batish DR, Kohli RK, eds. Invasive Plant Ecology. Boca Raton: CRC Press.

Richards CL, Bossdorf O, Muth NZ, Gurevitch J, Pigliucci M. 2006. Jack of all trades, master of some? On the role of phenotypic plasticity in plant invasions. Ecol Lett 9: 981-993.

Scheers K, Denys L, Jacobs I, Packet J, Smeekens V, Adriaens T. 2019. Cabomba caroliniana Gray (Cabombaceae) invades major waterways in Belgium. Knowl Manag Aquat Ecosyst 420: 22.

Scheffer M 2004. Vegetation. In: Usher MB, DeAngelis DL, Manly BFJ, ed. Ecology of Shallow Lakes. Dordrecht: Kluwer Academic Publishers, pp. 210-288.

Schooler S, Julien M, Walsh GC. 2006. Predicting the response of Cabombacaroliniana populations to biological control agent damage. Aust J Entomol 45: 327-330.

Schooler S, Cabrera-Walsh W, Julien M. 2012. Cabomba caroliniana Gray - cabomba. In Julien MH, McFadyen RE, Cullen J, eds. Biological Control of Weeds in Australia. Collingwood: CSIRO Publishing, pp. 108-117.

Shen N, Yu H, Yu S, Yu D, Liu C. 2019. Does soil nutrient heterogeneity improve the growth performance and intraspecific competition of the invasive plant Myriophyllum aquaticum? Front Plant Sci 10: 723.

Smith S, Küpper FC, Trinder C, Louca V. 2021. Assessing watermilfoil invasion effects on native macrophyte communities in North American lakes using a novel approach for macrophyte sampling. Knowl Manag Aquat Ecosyst 422: 1.

Son D, Cho K, Lee EJ. 2017. The potential habitats of two submerged macrophytes, Myriophyllum spicatum and Hydrilla verticillata in the river ecosystems, South Korea. Knowl Manag Aquat Ecosyst 418: 58.

Sousa WTZ. 2011. Hydrilla verticillata (Hydrocharitaceae), a recent invader threatening Brazil's freshwater environments: a review of the extent of the problem. Hydrobiologia 669: 1-20.

Taihu Basin Authority (TBA). 2019. Taihu Basin \& Southeast Rivers Water Resources Bulletin 2018 (in Chinese with English abstract).

van Kleunen M, Dawson W, Schlaepfer D, Jeschke JM, Fischer M. 2010a. Are invaders different? A conceptual framework of comparative approaches for assessing determinants of invasiveness. Ecol Lett 13: 947-958. 
van Kleunen M, Weber E, Fischer M. 2010b. A meta-analysis of trait differences between invasive and non-invasive plant species. Ecol Lett 13: 235-245.

Vilà M, Espinar JL, Hejda M, Hulme PE, Jarošík V, Maron JL, Pergl J, Schaffner U, Sun Y, Pyšek P. 2011. Ecological impacts of invasive alien plants: a meta-analysis of their effects on species, communities and ecosystems. Ecol Lett 14: 702-708.

Wang H, Wang Q, Bowler P, Xiong W. 2016. Invasive aquatic plants in China. Aquat Invasions 11: 1-9.

Wang J, Yu D, Wang Q. 2008a. Growth, biomass allocation, and autofragmentation responses to root and shoot competition in Myriophyllum spicatum as a function of sediment nutrient supply. Aquat Bot 89: 357-364.

Wang J, Yu D, Xiong W, Han Y. 2008b. Above- and belowground competition between two submersed macrophytes. Hydrobiologia 607: 113-122.

Weigelt A, Jolliffe P. 2003. Indices of plant competition. J Ecol 91: $707-720$

Wu H, Ding J. 2019. Global change sharpens the double-edged sword effect of aquatic alien plants in China and beyond. Front Plant Sci 10: 787.
Xu H, Ding H, Li M, Qiang S, Guo J, Han Z, Huang Z, Sun H, $\mathrm{He} \mathrm{S}$, Wu H, Wan F. 2006. The distribution and economic losses of alien species invasion to China. Biol Invasions 8: $1495-1500$.

Yu H, Wang L, Liu C, Fan S. 2018. Coverage of native plants is key factor influencing the invasibility of freshwater ecosystems by exotic plants in China. Front Plant Sci 9: 250.

Yu J, Zhen W, Guan B, Zhong P, Jeppesen E, Liu Z. 2016. Dominance of Myriophyllum spicatum in submerged macrophyte communities associated with grass carp. Knowl Manag Aquat Ecosyst 417: 24.

Zedler JB, Kercher S. 2004. Causes and consequences of invasive plants in wetlands: opportunities, opportunists, and outcomes. Crit Rev Plant Sci 23: 431-452.

Zhan A, Ni P, Xiong W, Chen Y, Lin Y, Huang X, Yang Y, Gao Y. 2017. Biological invasions in aquatic ecosystems in China. In: Wan F, Jiang M, Zhan A, eds. Biological Invasions and Its Management in China. Dordrecht: Springer, pp. 67-96.

Zhang Z, van Kleunen M. 2019. Common alien plants are more competitive than rare natives but not than common natives. Ecol Lett 22: 1378-1386.

Cite this article as: Huang X, Yu J, Liu S, Xie H, He H, Li K. 2021. Plant morphological traits and competition index comparisons of three invasive and native submerged plants. Knowl. Manag. Aquat. Ecosyst., 422, 11. 